\title{
A Study On Designing And Researching Multimedia Courseware In The Chinese School Video Dictionary
}

\author{
GUANGSHENG CHEN ${ }^{1, \mathrm{a}}$, NHO QUYET TRAN ${ }^{1, \mathrm{~b}, ~ *}$, NHO CUONG TRAN ${ }^{2, \mathrm{c}}$, THI THANH \\ HIEN NGUYEN ${ }^{2, ~ d, ~ Q U O C ~ D U N G ~ D U O N G ~}{ }^{3, \mathrm{e}}$ \\ ${ }^{1}$ Information and Computer Engineering College, Northeast Forestry University, China. \\ ${ }^{2}$ Vietnam National University of Forestry, Viet Nam. ${ }^{3}$ Military Technical Academy, Viet Nam \\ aemail: 271395688@qq.com, bemail: 3315435075@qq.com, \\ cemail: 1530218602@qq.com, ${ }^{\mathrm{d} e m a i l: ~ h i e n v k t @ y a h o o . c o m, ~}{ }^{\mathrm{e}}$ email: quocdung_mta@yahoo.com \\ *Corresponding author: Information and Computer Engineering College, Northeast Forestry University, \\ China. Email: 3315435075@qq.com
}

Key words: Chinese, video dictionary, multimedia technology.

\begin{abstract}
The Chinese school video dictionary-is a kind of teaching application software which is designed by using multimedia courseware. It focuses primarily on a combination of the multimedia technology and Chinese knowledge in school class. The programming realization was based on index data, data transfer, and efficient organization of data. In addition, to construct a video dictionary software is a goal of the designer. The dictionary database includes integrated thesaurus, exclusive pronunciation library and video library. The new Chinese school video dictionary considers four functions: query function, capturing function, vocabulary pronunciation function, and video display function. This paper aims at helping the teacher in teaching and many students in self-learning.
\end{abstract}

\section{Introduction}

Electronic dictionary is proposed in the late 20th century, when American began to research machine translation, because of one of the core translation systems is bilingual or multilingual electronic dictionary, also called machine translation dictionary. After the 1980s, with the popularity of PC, as well as the extensive spread of the internet in recent years and the continuous deepening of researches about machine translation, electronic dictionary was more and more interested. In recent years, based on multimedia technology for the use of the electronic dictionary the dictionary structure, form, language and other types of happened great changes, and gradually from the stand-alone version of the electronic dictionary to Internet single and combined with the development of the form, the more famous is Google Kingsoft cooperation version (Google and Kingsoft Corporation), Youdao, NetEase company, Lingoes etc. Over the world, there are many kinds of electronic dictionary, many companies are researching to design dictionary, but the school electronic dictionary is rare. In Vietnam, for the school's Chinese video dictionary does not exist due to: In first place, this kind of dictionary relates to education, therefore teaching method and content have strict requirements. Secondly, video relative to new words of Chinese classes in the school, so selection content of video is very important. Thirdly, its main effect is to serve to teachers teaching and students learning, but for other scholars it has not so high profit.

The study is a practical significance research on the effects of the promotion study ability upon the Chinese-Vietnamese language video dictionary especially upon multimedia courseware technology.

\section{Using Research Tools}

Visual Studio 2008 and Windows 7. 


\section{Design Idea}

The Thought Of Multimedia Courseware. In 1959, the United States IBM company developed the first computer assisted instruction (CAI) system, declared human beginning to enter the era of computer education. At present, the computer assisted instruction has been deeply entranced in the education of the school, the role of this technology has become increasingly prominent and has a very broad application prospects in the teaching work.

Courseware. courseware refers to the activities of the CAI, including the teaching content, accept the students' requirements and answers, guidance and control teaching activities and related teaching materials. In a broad sense, teaching software which has a certain teaching function can be called as the courseware, its function includes the following four aspects:

$\checkmark$ Provide for students a variety of professional knowledge;

$\checkmark$ Analyze the learning process of student, conduct processing and guiding students to learn all kinds of knowledge;

$\checkmark$ Improve the enthusiasm of students to participate in learning, to achieve a better learning effect;

$\checkmark$ Record the student learning data and update in order to achieve the digital learning process, help better control their learning process .

Multimedia Courseware. multimedia courseware and traditional multimedia software is not the same, it is a kind of teaching carrier, used to support the teaching of specific subjects, applicable to specific teaching objects. Multimedia courseware is the comprehensive use of text, graphics, animation and sound and other forms of teaching courseware. The multimedia courseware can be divided into three types, such as text, image and sound. It can be said that the multimedia courseware is based on the requirements of the teaching syllabus and teaching work, through the strict design, and the use of multimedia in the form of software as a form of courseware. With multimedia technology as the basis for the preparation of the design, the multimedia courseware, comprehensive utilization of text and image data, change the traditional courseware to text as the shortcomings of main way of expression, so that students can through a variety of visual and auditory senses to learn and improve learning efficiency. Multimedia technology has considerable potential, the use of "human-computer interaction" to improve the information transmission path, better control of information, also can make the understanding of students' thinking and information convey more closely, can also expand people in sequence, serial number and other information processing capabilities. Compared with the traditional single media, the involvement of multimedia can make the students learn more and more senses and the whole range of learning knowledge, and improve the ability and effect of communication. Understanding of multimedia courseware technology, not to understand the professional terminology, but to understand the use of multimedia interactive, sense of the full use, in order to achieve the best communication results.

The Innovation Of Multimedia Courseware Technology. From the complexity of the old algorithm to the requirements of learners and the teaching methods of teachers, the following simple algorithm is proposed:

Play Flash Courseware.

(1) The first new algorithm: direct play a flash (.swf) file AxShockwaveFlash1.Movie = "E: \\kejian1.swf"

(2) Second new algorithms: according to the path to write the path name, play a flash (.swf) file AxShockwaveFlash1.Movie $=$ TextBox.Text

Among them, TextBox is the place to write the path name of the courseware.

(3) Third new algorithms: according to the name of the courseware to write a Flash (.swf) file AxShockwaveFlash1.Movie = "C:\\Tudienl" + TextBox.Text + ".swf"

Among them, TextBox is the place to write the name of the courseware.

Play Audio, Video Courseware.

(1) The first kind of new algorithm: direct play an audio, video courseware 
AxWindowsMediaPlayer1.URL = "E:IVkejian.mp3"

AxWindowsMediaPlayer1.Ctlcontrols.play()

(2) The second kind of new algorithm: according to the path of the courseware to write the name, play an audio, video courseware

AxWindowsMediaPlayer1.URL = TextBox.Text

AxWindowsMediaPlayer1.Ctlcontrols.play()

Among them, TextBox is the place to write the path name of the courseware.

(3) The third new algorithm: according to the name of courseware writed, play a video lesson.

AxWindowsMediaPlayer1.URL = "C:॥Tudien।" + TextBox.Text + ".mp4"

AxWindowsMediaPlayer1.Ctlcontrols.play()

Among them, TextBox is the place to write the name of the courseware.

The Idea Of A New Kind Of Dictionary. Dependent classes in the Chinese school textbook knowledge, teaching methods and teaching ideology, learning and self-study expectations and previous dictionary to understand, established a new dictionary based on multimedia courseware technology: School of Chinese video dictionary.

Content Of Video Knowledge. Knowledge of video production assurance: first, teaching method; second, school class knowledge of Chinese regulations; third, with classes in the school of Chinese new words in the meet and match; fourth, with the native pronunciation, speaking very standard.

Dictionary Structure. The main result of the dictionary consists of 4 parts: the place where the new words are written, the search button, the result of the search, the window of the playing video. In addition, in order to more beautiful, attractive and so on, you can add some pictures, animation, or music etc,.

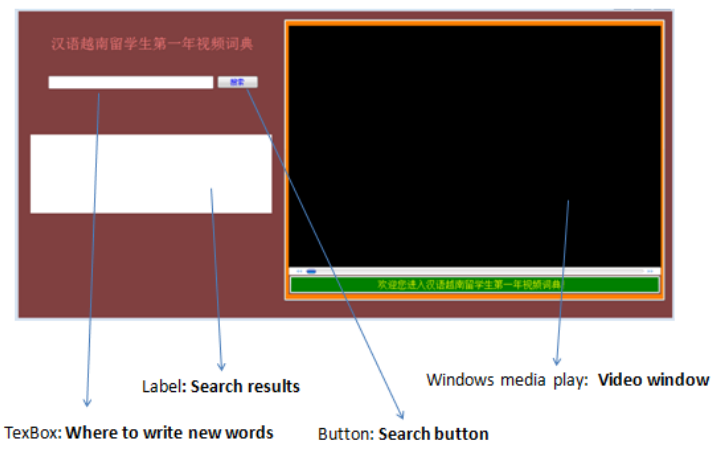

Fig. 1 Dictionary result chart

\section{Dictionary Design Method}

The First Step: The Design Of The Interface. At this stage, many production in the design will generally courseware design window to full screen size, but when the size of the form design is the entire screen, subject to different display resolution is not the same, proportion 4:3 and 16:9 proportion, courseware in actual use tend to lead to real interface effect is difficult to achieve the original design ideal state. Therefore, it is recommended to use the Picture Box control to design a relatively fixed size of the control, in order to replace the form to run the program, in order to avoid the impact of the above problems. At the same time, it also has a good, too much form can lead to visual basic compiling the dictionary in the running process of running speed greatly slow, and Picture Box control as a carrier for the preparation of the dictionary, running speed is greatly improved.

Second Step: Color Design. Want to make a good, content depth, students learning convenience are essential, but also pay attention to the use of color in the design of the dictionary, with the rationality. Due to the part of the teachers do not have a knowledge of color aesthetics and psychology, although the contents of the dictionary is good, but color is not scientific, reading and practical, easy to cause the students' visual fatigue, or is difficult to concentrate on my studies, and 
even cause influence to the students' mood, ultimately affect the effectiveness of teaching. Therefore, we are in the process of making dictionaries. We should pay attention to the use of color. The students may be president of the time to read the part of the design for the blue, black and other cold colors, will require students to mark as the focus of the content in red and other warm colors. Process design for the main color should not be too much used in a layout. It is best to about 3 . Do not exceed 5 colours, that color layout is not making people feel too fancy, and not make the interface tedious.

Third Step: Pictures, Animation Design. Production, we generally will be a static picture with Photoshop first processing. The most commonly used image format is generally .jpg and .gif. Using .jpg format can make the picture occupy less storage space, .gif format picture can show the transparent background. Some small animation can also be made with Image Ready software (Photoshop program in the software), but visual basic 2008 did not provide standard controls, gif animation, we can only use third-party controls anigif to run. In addition, flash animation is the courseware indispensable material type, can produce a lot of excellent animation by using flash software, for these animations can run within the visual basic program shockwaveflash controls, using the control within the recommend event, in the form of events to achieve interaction between visual basic and flash animation. The following is a deep analysis of the connection technology of shockwave flash and visual basic.

Right mouse $\rightarrow$ Click on the Visual BasicToolbox $\rightarrow$ Choose Item $\ldots \rightarrow$ COMComponents

$\rightarrow \square$ Shockwave Flash Object C: \Windows $\backslash$ SysWOW64\Macromed $\backslash . . . \quad$ Shockwave Flash

In the Visual BasicToolbox, select Shockwave Flash Object.

(1) The first method: Open the software immediately broadcast a Flash (.swf) Main code:

PrivateSub Form1_Load(ByVal sender As System.Object, ByVal e As System.EventArgs) HandlesMyBase.Load AxShockwaveFlash1.Movie = "E:I\kejian1.swf"

EndSub

(2) Second ways: In the Textbox insert the Flash path name, push button (Button) to immediately play a Flash (.swf)

Main code:

PrivateSub Button1_Click(ByVal sender As System.Object, ByVal e As System.EventArgs) Handles Button1.Click

AxShockwaveFlash1.Movie $=$ TextBox1.Text

EndSub

\section{The Fourth Step: The Design Of Audio And Video.}

Right mouse $\rightarrow$ Click on the Visual BasicToolbox $\rightarrow$ Choose Item . . . $\rightarrow$ COMComponents $\rightarrow$ Vindows Media Player C: $\quad$ Windows $\backslash$ system32/wmp.dll Windows Media...

On the Visual BasicToolbox, select Windows Media Player

Audio Design. directly in the form, insert the Windows Media player function, when playing it is not allowed to display and do not see its control. The following is the audio (.mp3) and analysis connection technology of VISUAL BASIC:

(1) The first method: Open the dictionary to play audio (often in the background design)

During design, using the Sent to Black function to put the Windows Media Player on the back of background or we can use the command: AxWindowsMediaPlayer1.Hide()

Main code:

PrivateSub vuihoc_Load(ByVal sender As System.Object, ByVal e As System.EventArgs) HandlesMyBase.Load

AxWindowsMediaPlayer1.Hide()

AxWindowsMediaPlayer1.URL = "E:I\kejian.mp3"

AxWindowsMediaPlayer1.Ctlcontrols.play()

EndSub 
(2) Second way: Push button to play audio

During design, useing Sent to Black function to put the Windows Media Player on the back of the background or we can use the command: AxWindowsMediaPlayer1.Hide()

Main code:

PrivateSub Button1_Click(ByVal sender As System.Object, ByVal e As System.EventArgs) Handles

Button1.Click

AxWindowsMediaPlayer1.Hide()

AxWindowsMediaPlayer1.URL = "E: Ikkejian.mp3"

AxWindowsMediaPlayer1.Ctlcontrols.play()

EndSub

Video Design. enter the name of the video in the Textbox, push button immediately play the video (.mp4, .mpg, .avi, .wmv, etc,.)

Main code:

PrivateSub Button1_Click(ByVal sender As System.Object, ByVal e As System.EventArgs) Handles

Button1.Click

AxWindowsMediaPlayer1.URL = "C:\\udien\" + TextBox.Text + ".mp4"

AxWindowsMediaPlayer1.Ctlcontrols.play()

EndSub

\section{The Research Results Of The Chinese School Video Dictionary}

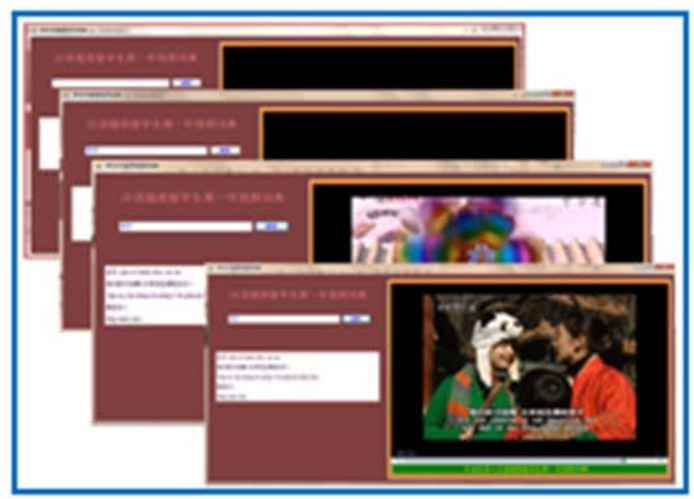

Look for the new words of “饺子”

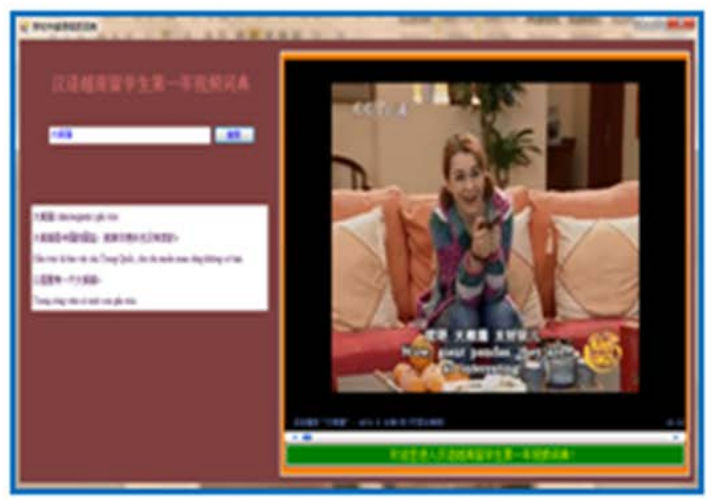

Look for the new words of “大能猫”

Fig. 2 Look for the new words

\section{Summary}

The feasibility of applying multimedia courseware technology to designing Chinese school video dictionary is giving out ideas and methods. As we know, multimedia courseware technology based on the emergence of the Chinese school video dictionary brought the convenience, which attractive teaching methods of Chinese knowledge by every student. The designing process is fully illustrated all the search, pronunciation and video broadcast function in the paper. Further research purposes is to help the teachers improving the ability, technology and method using design dictionary, as well as they can design a appropriate expected dictionary by themselves. The goal of the research was to obtain a more usable Chinese school video dictionary for education and teaching. Based on the results of the study, we conclude that the new Chinese school video dictionary design can be an effective solution for Vietnamese students learning Chinese and develop Chinese in Vietnam school. 


\section{References}

[1] Deitel, Vietnam FPT University, Visual Basic 2008, Vietnam Knowledge Press, (2013).

[2] M. Steiner, M. Blaschke, M. Philipp and T. Schweigert, Make test process assessment similar to software process assessment - the Test SPICE approach, Journal of Software: Evolution \& Process, 24 (5) (2012) 471-480.

[3] Lin Qingsong, The Application of Multimedia Technology in Web Education. Physics Procedia 33 ( 2012 ) 1553 - 1557

[4] Zhao Yibo and Lu Zhengdao, International Journal of Signal Processing, Image Processing and Pattern Recognition Vol.9, No.4 (2016) 193-202.

[5] Shao Haoshu, Design of a British Parliamentary Debate timer based on Visual Basic, China University of Mining and Technology, Jiangsu Xuzhou, (2015). 